\section{WEB PLAGIARISM: EMPIRICAL STUDY}

Alexander E. Voiskounsky

Lomonosov Moscow State University

Moscow

A questionnaire measuring web plagiarism (or academic cheating), worked out by Underwood and Szabo (2003) has been adapted and applied to the population of undergraduate science students in Russia. The students at four technical universities are questioned ( $\mathrm{N}=292)$. The study shows the students perform webplagiarizing, i.e. take materials from the Internet and hand these materials in as their own assignments. Russian students are reportedly competent in the use of the Internet; they report to have rather few moral barriers towards plagiarizing they believe most of their mates do the same; they are not sure their tutors are able and willing to recognize cheating; finally, they are competent enough in English and are hypothetically able to plagiarize in two languages.

Keywords: plagiarism, cyberethics, moral development, science students, gender academic year

\section{Web Plagiarism as a Cyberethics Problem}

The advance of information and communication technologies cause both new moral problems and new unexpected aspects of older problems in the field of moral behavior. Beginning with the Internet and WWW era, a new field of research and practical work is being developed under the name of cyberethics. Cyberethics is usually understood as rules of right and lawful behavior in online environments. Most sources display cyberethics as a broad field dealing with computer fraud, online porn and harassment, identity theft and privacy violation, hacking/carding/ phreaking/cracking and software piracy, non-authorized surveillance and (cyber)vandalism, right/left online extremism and hacktivism, spamming, blackmailing and disseminating junk email, plagiarism and copyright infringement, fraudulent online banking, cybersquatting and

The study was supported by the Russian Foundation for Humanities, project № 09-0601029a. (cyber)stalking, spoofing and phishing, flaming and trolling, writing and dissemination viruses and worms, etc. (Langford, 2000; Quigley, 2005; Schultz, 2006; Tavani, 2004).

Considerable amount of studies dealing for example with academic offences, cheating, and dishonesty has been done in the field. In a study held in California it was shown that illegal computer-related behaviors, ranging from copying of licensed software pieces to changing/stealing data in personal computers of other persons, are widely spread and often initiated by middle- and high-school students (McGuire, et al., 2002). University students' cheating was found to depend on IT-related cases and expected awards (Ruf, and Thomas, 2003). Attitudes towards illegal software copying were shown to depend upon such factors as perceived personal gain (e.g., social acceptance, favour, repay of debt, etc.), altruism, and perceived negative consequences (Ang, and Lo, 2001). Combinations of legal or professional factors, personal beliefs and attributes (i.e., religious values, morals, experience, etc.), and social environments were found to impact ethical decision making in the IT environment (Cronan, and Kreie, 2000).

Culture is widely believed to represent a valuable factor in committing illegal and/or unethical actions. In business environments, the representatives of various cultures report and express varying degrees of tolerance towards unethical behavior patterns (Kolb, et al., 2003). Attitudes towards the possibility of computer/Internet abuse may vary greatly, dependent on cultural backgrounds (Voiskounsky et al., 2000; Voiskounsky, 2004). Religious beliefs as well influence the likelihood of software piracy and deterioration of privacy (Debnath, and Bhal, 2002). In a research held in Thailand, it was shown that students' demographic parameters, such as age and gender, as well as experience in the use of IT-related equipment, particularly computers, and particularly at home, correlate significantly with the likelihood of software piracy; the moral level of the university faculty seems not to be related to the students' cyberethics scores (Kini, et al., 2003). Moral judgments referring to the IT-related environments have been shown to depend on adult subjects' age, sex, and position in administrative hierarchy (Kim, 2003). Loch and Conger (1996) also report gender differences in the moral use of computers - differences both in an ethical decision-making and in the reasons which affected the deci- 
sions made by men and women. In a comparative study held recently in the USA and in China (Jackson, et al., 2008) it was stated that the Chinese participants find morally questionable online behaviors to be more acceptable, compared to the USA participants, with the only exception of the videogame violence - the USA participants, especially males, find it more acceptable compared to the Chinese participants.

The most general conclusion says that culture dependent attitudes towards software license infringement, use of viruses, and misuse of corporate computing resources differ greatly. At the same time the results of a study held in several countries make it evident that there is not a single culture, out of the nine investigated, whose representatives exhibit totally "perverted" (compared to what is though to be correct in the Great Britain or in the USA) moral attitudes in the IT field (Whitman, et al., 1999).

This paper is devoted to new trends in academic plagiarism, related to taking ready-made pieces from the Internet and inserting these pieces into one's assignment and/or presenting a whole piece as a homework. Academic plagiarism, being an obvious part of cyberethics, is a world-wide problem; new information technologies make it quite easy to copy and paste someone's work and present it, or a part of it, as one's own work. Also, it is nowadays harder for a teacher/tutor to recognize a fraud, due to a great amount of possible web sources which might have been used to commit fraud.

On higher levels of academic hierarchy plagiarism is a more or less rare evil, since the reviewers are competent, and the authors have easy enough access to the dissertations/books/theses/scholar, papers submitted to diverse foundations, boards and publishers, and are often able and most often willing to tell the truth. On lower levels the problem is serious indeed. Many universities have already equipped the faculty with specialized search engines which compare any newly submitted written work with the storage of previously submitted works, and find out the preceding work(s) which substantially overlaps with the new one. In the latter case the new work would be rejected, and disciplinary measures would be taken against the student who attempted to hand it in. The search engines need to update the storage constantly, and their effectiveness might anyway be questioned; the limits of reliability of these instruments should be investigated.
The word "plagiarism" is certainly known to many pupils/students, but they usually do not relate it with their habitual practice: for example, on May $28^{\text {th }}, 2004$ the Webuser told a story of Michael Gunn, a former student at the University of Kent, who claimed he was not aware that his written works were obvious cases of plagiarism (Earl, 2004). The student, who was said would not be awarded his degree, was desperate. His mates and professors uttered they believe that Michael Gunn was not exceptional; plagiarism is believed to be widespread and epidemically developing. New Since the copy, cut and paste techniques are taught in elementary school, the must "never do plagiarism" needs to be competently explained to all the generations of students, beginning with the youngest, and the explanations need to involve new technology-driven cases.

Different views on legal and moral aspects of the Internet-related plagiarism, on personal and situational factors which make it possible and even welcomed in students' communities, are discussed by Szabo and Underwood (Szabo, and Underwood, 2004; Underwood, and Szabo, 2003) - this study has significantly influenced our work. Since it was shown by many authors (see above) that culture is an important factor in (cyber)ethical/unethical behavior, our goal was to investigate the students' views on plagiarism and their practice in Russia. First we have to discuss the specifics of the Internet-related plagiarism in Russia.

Plagiarism is a well-known Russian term, it is most often referring to stealing pieces of music or fiction, and rather rarely - to academic issues. There are no good equivalents of terms like 'academic cheating', 'academic offences' or 'academic dishonesty', but for copyright infringement or plagiarism. Thus, the very term 'plagiarism' is widely known and well understood in Russia. What is important, the term is not often referred to University students' academic work.

Cyberethic problems seem to be universal, including the use of new technologies for cheating in academic environments. On the other side, these problems might in a way be culture-dependent. One may suppose that the Internet plagiarism is no less usual type of behavior in Russia than it is elsewhere. Right now we cannot say whether this is true or not. First we need to collect empirical data in some comparable way. The empirical part of the paper is an advance in this direction. 
The aim of research was to restrict the broad enough theme and to carry out a study on the use of plagiarism from the Web in Russia. The population under investigation included undergraduate science students.

\section{Participants}

Undergraduate students of science departments at four different Moscow universities were volunteered to participate in the study. As many as 292 students completed a 13-item questionnaire. Characteristics of the sample are presented in Table 1.

\section{Gender of the participants and number of years}

Table 1 they study at the university

\begin{tabular}{|c|c|c|c|c|c|}
\hline & \multicolumn{2}{|c|}{ Males } & \multicolumn{2}{c|}{ Females } & Total \\
\cline { 2 - 6 } Year 1 & 42 & $38,5 \%$ & 67 & $61,5 \%$ & 109 \\
& $26,9 \%$ & & $49,3 \%$ & & $37,3 \%$ \\
\hline \multirow{2}{*}{ Year 2 } & 47 & $46,5 \%$ & 54 & $53,5 \%$ & 101 \\
& $30,1 \%$ & & $39,7 \%$ & & $34,6 \%$ \\
\hline \multirow{2}{*}{ Year 3 } & 67 & \multirow{2}{*}{$81,7 \%$} & 15 & $18,3 \%$ & 82 \\
& $42,9 \%$ & & $11,0 \%$ & & $28,0 \%$ \\
\hline Total & 156 & $53,4 \%$ & 136 & $46,6 \%$ & 292 \\
\hline
\end{tabular}

\section{The questionnaire}

The 13-item questionnaire was used, based on the 12-item questionnaire designed and used in the Szabo and Underwood (2003) and Underwood and Szabo (2003) studies. One question (№ 13) was added, namely, 'What is your level of competence in English?' The initial questionnaire was designed by Underwood and Szabo (2004) to measure:

- general familiarity of respondents with the Internet, and frequency of its use, especially for learning (questions 1-3);

- frequency of the Internet misuse in the form of plagiarism, attitudes towards plagiarism, and estimations of the risk associated with this form of cheating (questions 4-9);

- acceptability and secrecy of this form of plagiarism (questions 10-12).
Depending on the questions, a 3-, 4-, or 4-point Likert scale was provided to give the resulting marks. Additionally, in the printed questionnaire it was requested to indicate the participants' gender; an academic year was fixed since the study was held in academic settings (see the Procedure).

The initial 12-item questionnaire used in the abovementioned study held in the UK was translated into Russian, and administered within two small samples (6 and 7 persons) representing the same population of undergraduate students. The members of these two samples were interviewed in order to learn whether they understood the questions correctly. Based on the evidences gained in these interviews, the translated version of the questionnaire was corrected, and made ready to use.

\section{Procedure}

Though research was held at different classrooms of four Moscow universities, the procedure was the same: upon agreement, four selected lecturers introduced an investigators' assistant to the participants, the assistant informed students about the aims of the study and distributed the printed forms with the questionnaire. Students were informed that the questionnaire was anonymous, and asked to volunteer in the study, i.e. to answer all the questions as honestly as possible and without consultations with peers. The students were assured that the aim of research was not to identify participants, but to acquire the views of as much as possible participants. After collecting the filled in forms, the assistant left the room, no longer than 10-12 minutes after the class started.

\section{Results}

The responses represent closely related but nevertheless distinct units of information; thus, the results are presented separately for each question. Gender and academic year differences are reported when statistically significant.

The first three questions showed that the majority of participants were skilled enough to use the Internet. The replies to the $1^{\text {st }}$ question ("How familiar are you with using the Internet?") show that as many as 17.5 percent of students reported no familiarity with the Internet (11.5 percent men and 24.3 percent women; over 20 percent of first- 
and second-year, and only 3.7 percent of third-year students), about the same number of participants (17 percent) report they are able to search information, whereas almost two thirds of them could at least search, copy and save files from the Internet (including 44 percent of those who report they are familiar with all the aspects of the Internet). Gender $\left(\chi^{2}(3)=29,219, \mathrm{p}<.001\right)$ and academic year $\left(\chi^{2}(6)=35.619, \mathrm{p}<.001\right)$ differences are significant: men and higher-year students report greater familiarity with the Internet, compared to women and low-year students. Better familiarity with the Internet, reported by the third-year students, might also correspond with uneven gender presentation among thirdyear students: Table 1 shows that four out of every five highest academic level students are males (whereas less than half of first- and second-year participants are males), and men report better familiarity with the Internet $(M=3.22, \sigma=1.03)$, compared to females $(M=2.55, \sigma=1.15)$.

From the reports to the $2^{\text {nd }}$ question ("How often do you browse the Internet?") it is evident that over half of students (56.5 percent) use the Internet once a week or more, including 40 percent of those who use it several times a week. A small amount of students who reported, while answering to the first question, no familiarity with the Internet (17.5 percent) manage nevertheless to use it in some way, since only 15.1 percent students (9.6 percent males, 21.3 percent females) report they never at all use it. Admittedly, 2.4 percent students use information from the Internet, which someone else has searched for them. About 13 percent of participants report they do not use the Internet more often than several times per a year.

Gender differences are statistically significant $\left(\chi^{2}(4)=32,319\right.$, $\mathrm{p}<0.001)$ : males use the Internet more frequently than women $(\mathrm{M}=$ 3.96, $\sigma=1.37$ for men, $M=3.04, \sigma=1.47$ for females). Negative correlation $(r=-.317, \mathrm{p}<.01)$ also shows that men are more frequent Internet users. Frequency significantly increases with the academic year $\left(\chi^{2}(8)\right.$ $=45.034, \mathrm{p}<0.001): 52$ percent of third-year students use the Internet more than once a week compared to 30 percent of second-year and 34 percent of first-year students. Peculiarly, the amount of the most intense users decreases from the first to the second academic year.

Frequency of the Internet use for course work differs from the preceding results: replying to the $3^{\text {rd }}$ question ("How often do you use infor- mation from the Internet in preparing your assignments?") 27.4 percent of participants report they never use it for learning goals, and 31.1 percent use it often enough - once a month or more (including 5 percent of those who use it about once a week and 3 percent of those who use the Internet several times a week); as many as 42 percent use it several times a year. No significant gender or academic years specific differences are found; thus, males and females, and in general all the undergraduate students report equally rare interest in the use of the Internet while preparing their course work. A weak negative correlation $(r=-.113)$ gives a hint that younger students tend to use the Internet more often, compared to third-year students; this hint proves to be insignificant $(\mathrm{p}=.054)$ though it is rather close to $\mathrm{p}=.05$.

The remaining questions are more specific in touching the theme of plagiarism. The next two questions are exploring the participants' willingness to copy/paste information from the web sources and illegitimately present it as their homework. While replying to the $4^{\text {th }}$ question ("How often do you use the COPY / PASTE function to embed information from the Internet, without modification and/or proper referencing, into your assignments?"), students report they rarely use unmodified information from the Internet for preparation of assignments: 11.7 percent report to do it once a month or more often (half of them - once a week or more often), and about two thirds (63.4 percent) report they never do it; 24.9 percent report they do it a few times a year. Gender differences are insignificant. Greater academic year students are less likely to use unmodified Internet information for learning goals: 48.6 percent of first-year students report they do it, compared to 34.7 percent of secondyear and 23.2 percent of third-year students. Thus, moving from the $1^{\text {st }}$ to the $3^{\text {rd }}$ academic years, students decrease the amount of plagiarism (i.e., the number of copy/paste actions without proper referencing) related to their course-work by two. This between-year difference is significant $\left(\chi^{2}(8)=25.256, \mathrm{p}<0.001\right)$.

When asked whether they would misuse (i.e., use in unmodified form and give no proper references) any information downloaded from the Internet in case it would save them from a failure, half of students (51 percent) chose the reply probably. One third (32.9 percent) reply they would rather face failure, and 16 percent report that under condi- 
tions of failure they would certainly use the copy/paste function and make no references, i.e. plagiarize (the $5^{\text {th }}$ question is "If it could save you from failing a module, would you use the COPY / PASTE function to use the readily available information from the Internet, without modification and/or proper referencing, into your assignment?"). Again, the results provide neither significant gender nor between-academic-year differences. Thus, the pressure of possible failure seems to cause the students' (mis)behavior, with the exception of one third of students who report they would not plagiarize anyway.

The next question broadens the range of conditions under which a student might prefer to plagiarize (Figure 1). Only 6.8 percent students reply they would under no circumstances use any readily available on the Internet information to present it as their assignment, and 24 percent replied alternatively, that they would do it at any time. Slightly more (25.3 percent) students believe that difficulty of an assignment and 4.1 percent - its laboriousness, is a good excuse for plagiarism. About one third (31.5 percent) report they would do it to meet an urgent deadline, and 8.2 percent - to escape a failure. To compare, in giving answers to the preceding (the $5^{\text {th }}$ ) question, 16 percent students report

Under which of the following conditions would you use information readily available on the Internet to hand in as your work or assignment?

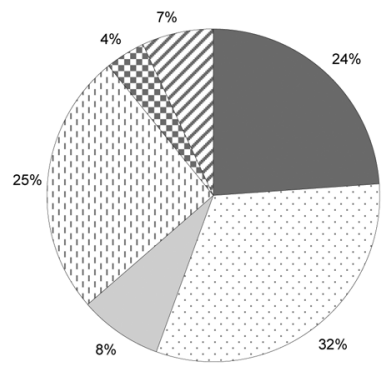

$$
\begin{aligned}
& \text { at any time } \\
& \text { if I need to meet an urgent } \\
& \text { deadline } \\
& \text { only if it would save me from } \\
& \text { failing } \\
& \text { if an assignment is too difficult } \\
& \text { if an assignment is too } \\
& \text { laborious } \\
& \text { under no circumstances }
\end{aligned}
$$

Figure 1. Type of conditions leading to unacceptable academic behavior $(\mathrm{N}=292)$

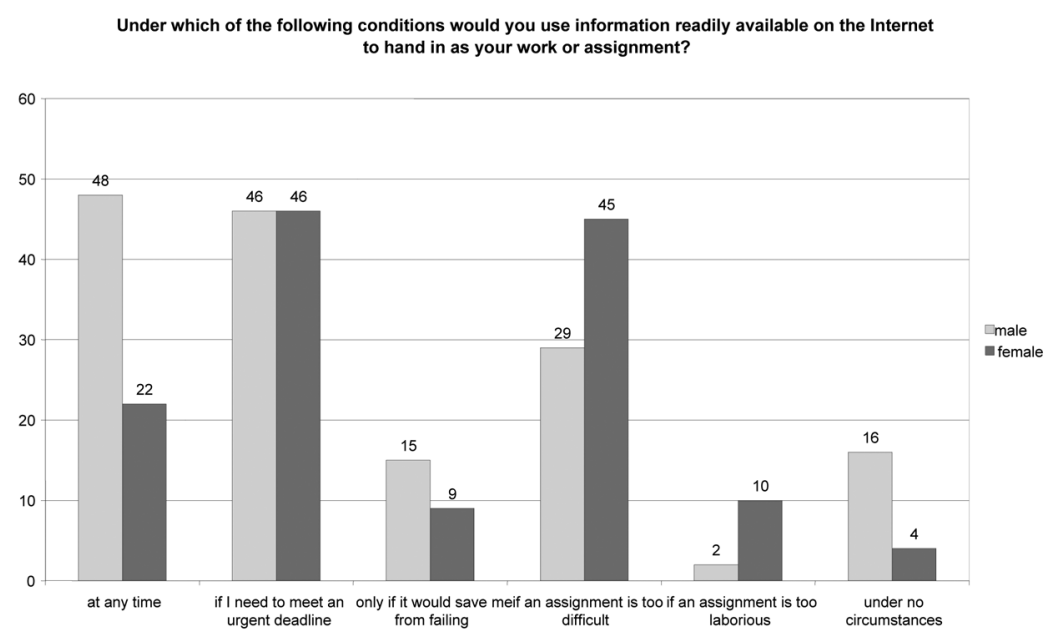

Figure 2. Students' readiness to perform unacceptable academic behavior by condition and gender $(\mathrm{N}=292)$

they would plagiarize under a pressure of a failure. Most of about 40 percent $(31.5+8.2)$ students who report they would plagiarize under conditions of meeting an urgent deadline or escaping a failure seem to be recruited out of the group of those who replied to the preceding question probably.

Significant gender $\left(\chi^{2}(5)=25.902, \mathrm{p}<0.001\right)$ differences are found. Males tend to expose more moral (every four -80 percent - out of five of those who would under no circumstances plagiarize are males) and at the same time more risky (males comprised over two thirds - 68.6 percent - of those who would plagiarize at any time, and about two thirds - 62.5 percent - of those who would plagiarize to escape failure) behaviors. Females outnumber males when they are able to find special excuses to plagiarize, for example when they believe the assignment is too laborious (83.3 percent females) or too difficult (60.8 percent females). Appropriate data are presented also at Figure 2 and Figure 3.

Data referring to the reported likelihood of plagiarism of students differing in academic year are presented at Figure 3. Though the differ- 


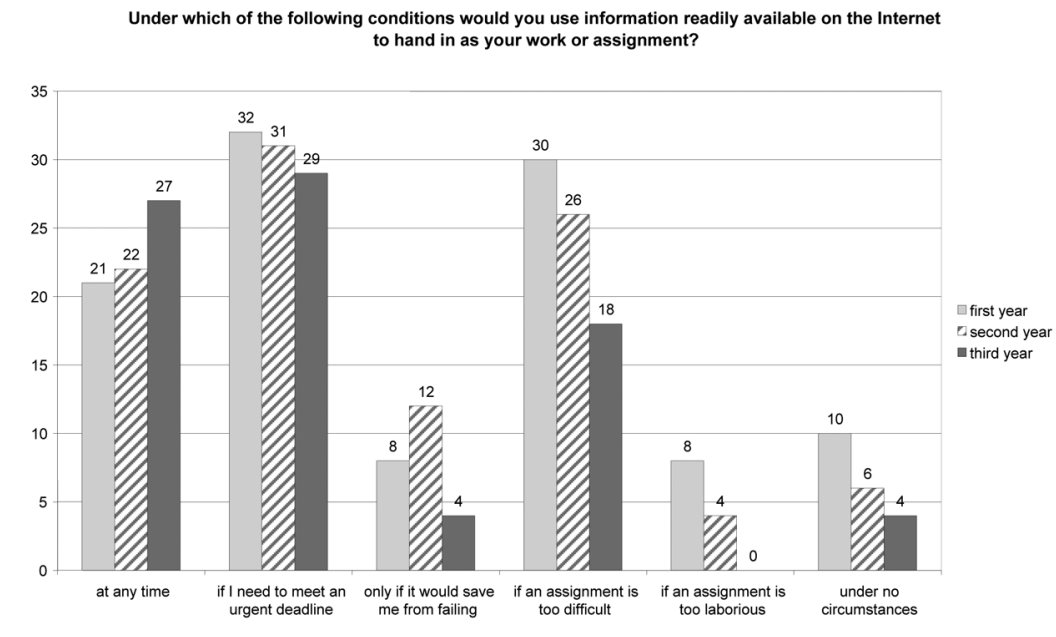

Figure 3. Students' readiness to perform unacceptable academic behavior by condition and academic year $(\mathrm{N}=292)$

ences are not significant, the tendencies are evident enough. Namely, the third year students, being mostly males, report to be

- less dependent on excuses,

- more likely to plagiarize at any time, and

- less likely never (under no circumstances) to do it.

The next small block of questions refers to the University lecturers and tutors, i.e. those who represent the opposition to the students' academic cheating. They have to be fully competent to recognize and stop any kind of cheating, but in fact they are sometimes not. Academic cheating fills a gap between the students' expertise in abusing new media in order to succeed in plagiarizing and the tutor's incompetence or lack of time to make the adequate inquiries and recognize the cheating

In the next question (namely, "Do you think that your tutor's expertise in using the Internet would enable him/her to find out whether you have used information taken directly from the Internet, without referencing, in your assignment?") the students are requested whether they believe that their tutor is competent enough to recognize that a student uses in his/her assignment some information pieces downloaded from the Internet and while doing this do not provide proper references. The results show that only 13 percent of students believe the tutor would not recognize their cheating, and twice as many, 27 percent, report that the tutor is likely to find it out. The majority, 60 percent, is not certain and thus reply probably. No gender or academic year differences prove to be significant.

Additionally to questioning the respondents' beliefs about their tutor's competence in recognizing plagiarism, the students have been asked whether they think that the tutor would indeed recognize in their assignments pieces of information taken from the Internet without proper referencing ("Do you think that the lecturer(s) would find out if you would hand in an assignment that contains information directly taken from the Internet?"). Again, the majority (65 percent) of participants choose the option probably, whereas a lesser (10.3 percent) amount of students reply that the tutor would not recognize information taken from the Internet. As many as 24.7 percent of participants believe that the tutor is able to find out the cheating in the student's assignment. Unlike the results referring to the preceding question, gender differences turn out to be statistically significant $\left(\chi^{2}(2)=12,097, \mathrm{p}<.002\right)$ : males' belief that the tutor would not recognize their cheating is five times greater (25 percent) than the females' belief ( 5 percent). Weak correlation $(r=.139$, $p=0,017)$ shows the same trend. No academic year differences have been found to be significant.

The next question refers to the students' estimations of the risk/ benefit ratio of being caught plagiarizing ("Could the benefits of using information from the Internet, as your own work, outweigh the risk of being caught with plagiarism?"). Only 28.8 percent reply that the risks outweigh the possible benefits, whereas every fourth (24.7 percent) student places the possible benefits above risk. The rest of the students, i.e. about half of them, choose the option probably. Gender and academic year differences in replies to the question are insignificant. The variety of females' replies is nevertheless statistically significant $\left(\chi^{2}(2)=21,897\right.$, $\mathrm{p}<.001)$ : females more often, compared to the random selection, choose the option probably. The same with the first year students' replies: the 
option probably is chosen significantly more often $\left(\chi^{2}(2)=23,468\right.$, $\mathrm{p}<.001)$.

Almost every student expects that he or she are not unique in expressing mostly positive attitude toward web plagiarism. In replying to the next question ("Do you think that some of your classmates use (or have used) information obtained from the Internet, in an unmodified format and without referencing, in their assignments?"), only 6.2 percent of participants express belief that their mates and peers do not use information taken from the Internet in their assignments without proper references. As many as 69.9 percent believe the mates illegitimately use information taken from the Internet, whereas 23.9 percent tell they are not sure. There are no significant differences between views expressed by males and females, and also between views expressed by students of different academic years.

In the next question the students have been overtly asked if they would feel guilty of plagiarizing ("Would you feel guilty about using information taken from the Internet as your work?"). A bit more than half of the participants accept that they might acquire this feeling: 28.4 percent of students have replied that they would certainly feel guilty handing information taken from the Internet, as their own work, whereas 27.1 percent have reported that they would possibly feel guilty. About half of the students (44.5 percent) report that they certainly would not feel guilty about plagiarism.

No statistically significant differences in the distribution of response categories between males and females are found, whereas the distribution of response categories characterizing males only is statistically significant $\left(\chi^{2}(2)=11,692, p<.003\right)$ : taken all those who report that they would not feel guilty plagiarizing, 55.4 percent are males and 44.6 percent females. Thus it is easy to admit that males are less prone, compared to females, to feel guilty committing plagiarism. No significant differences in feeling guilty between the replies given by students of first, second and third academic year are found, though a weak correlation $(r=.157, \mathrm{p}=.007)$ corresponds to a tendency: replies "yes" increase from the first to the third years, accompanied by a decrease of replies "no" (the "no"/"yes" proportion is 52.3/20.2 percent first-year, 41.6/28.7 percent second-year, and 37.8/39.0 percent third-year students); the

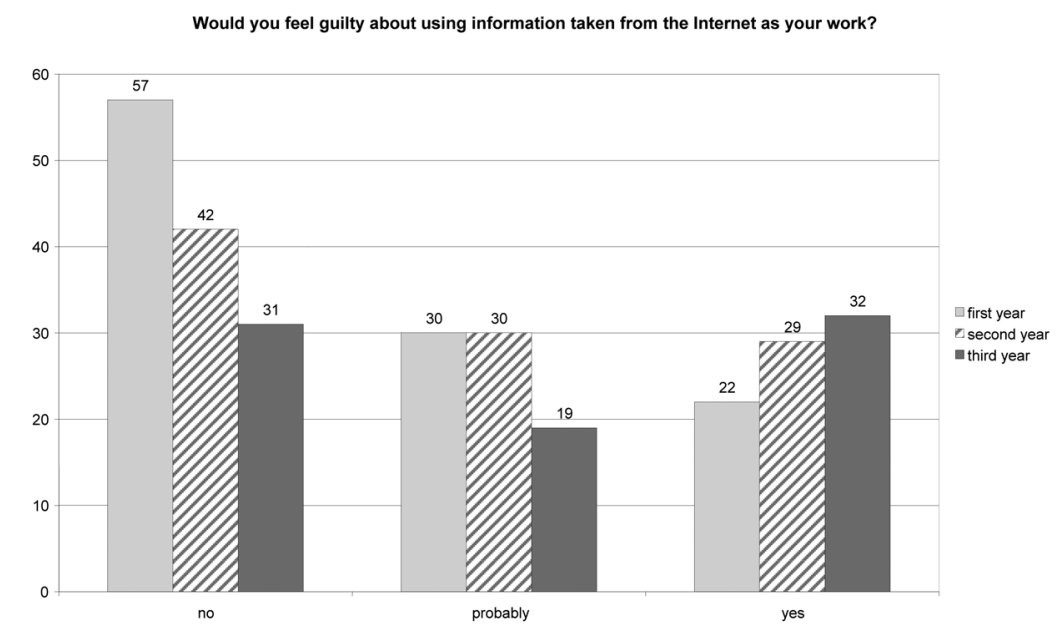

Figure 4. Students' self-reported level of feeling guilty of performing plagiarism, by academic year $(\mathrm{N}=292)$

proportion of neuter replies is about the same - see Figure 4. Indeed, the means and standard deviations increase: for the first-year $\mathrm{M}=1.68$ $(\sigma=.792)$, for the second-year $M=1.87(\sigma=.833)$, for the third-year students $\mathrm{M}=2.01(\sigma=.882)$. This tendency seems worth mentioning, since the third year students are mostly males, and in general males less often report they feel guilty, compared to females.

All the students who report they feel guilty, or non-guilty of plagiarizing, or else give neuter replies, may feel nevertheless uneasiness in telling their mates that they perform academic cheating. Thus, a special question has been asked, namely "Would you tell anyone (i.e., friends) if you were to plagiarise information from the Internet?" The results are somehow embarrassing, since only 13 percent of students report he or she would not tell others about plagiarism, whereas 64.0 percent report they would tell, and 23 percent students report they would probably tell friends about plagiarism. The results do not significantly differ by gender and by academic year, although there is a non-significant tendency toward a gradual decrease of positive replies from the first to the third academic year. 


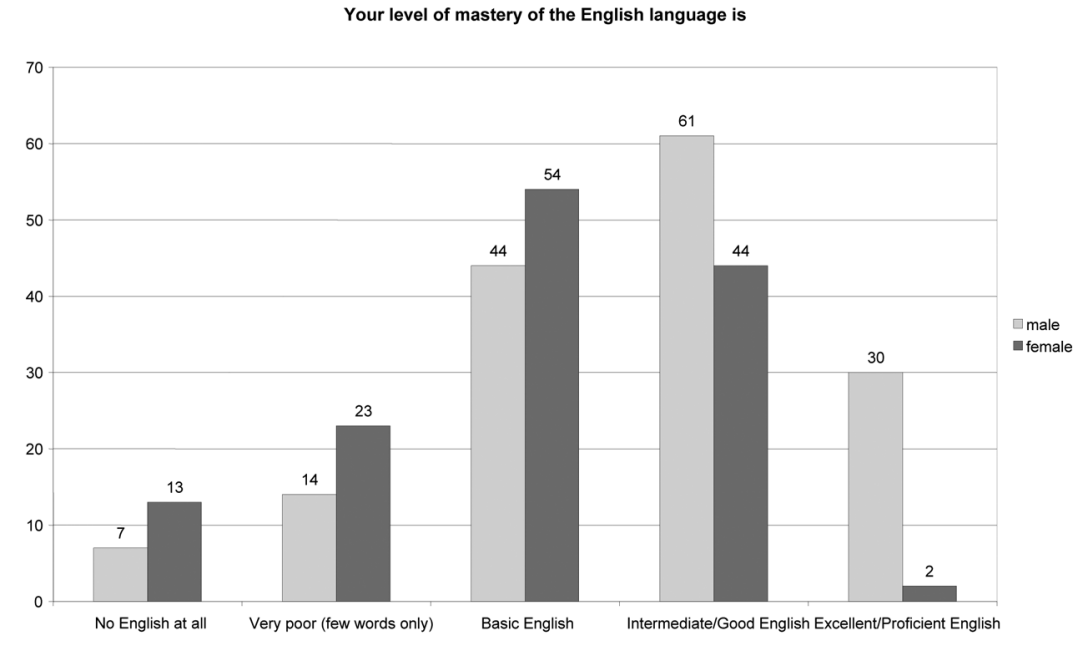

Figure 5. Students' self-reported competence in English language, by gender $(\mathrm{N}=292)$

Lastly, the students have been asked about their level of mastery of the English language; evidently, this question makes sense only in non-English speaking countries. The background of this question is that on the Internet there is much more information in English than in any other language, and thus those who have better mastered English have an advantage over less fluent speakers/readers of English, i.e. may turn to much more numerous web sources for committing plagiarism.

The results show that the students report good enough mastery of English: 80.6 percent report the level of Basic English and above (Intermediate/Good English or excellent/Proficient English), whereas only 6.8 percent choose the option "no English at all (few words only)" and 12.6 percent report their command of English is "very poor". At the same time not too many students - 11 percent - report their English being excellent.

Males report greater competence in English than females: $\mathrm{M}=3.60$ ( $\sigma=1.04)$ for males, and $\mathrm{M}=2.99(\sigma=.97)$ for females; negative cor-

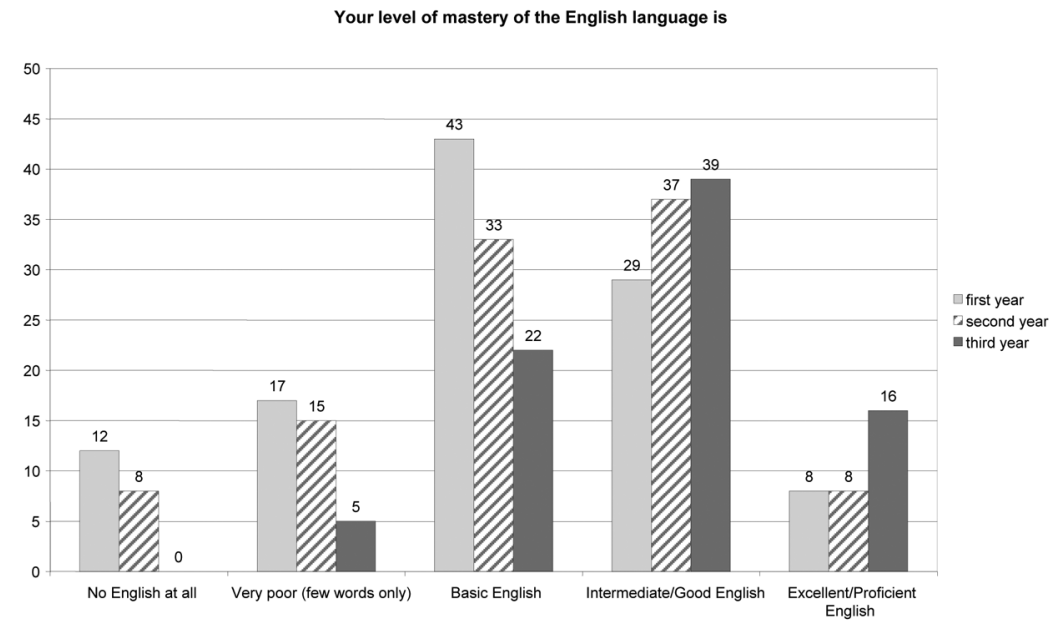

Figure 6. Students' self-reported competence in English language, by academic year $(\mathrm{N}=292)$

relation $r=-.293(\mathrm{p}<.01)$ shows that males' mastery of the English language is greater than that of females.' Over half of males, 58.3 percent, and only 33.9 percent of females report their level of mastery as Basic English and above; "no English at all" report 4.5 percent of males and 9.6 percent of females. Between-gender differences are statistically significant $\left(\chi^{2}(4)=31.038, p<.001\right)$. More detailed data as judged by gender are presented at Figure 5.

Differences in the distribution of the response categories between students of various academic years are statistically significant $\left(\chi^{2}(8)=\right.$ 28.070, $\mathrm{p}<.001)$, with correlation $r=.283(\mathrm{p}<.01)$ showing that the greater the academic year, the better is the reported level of students' mastery of the English language. Indeed, as is shown at Figure 6, the level of Basic English and above is reportedly characteristic for 33.9 percent of first year students, 44.5 percent of second year students, and 67.1 percent of third year students. On the contrary, among those who reports that he or she do not know English at all there are 11.0 percent of first year students, 7.9 percent of second year students, and not a one third year student. 


\section{Discussion}

First we discuss the most general result: whether Russian undergraduate science students are heavy plagiarizers. At the first glance, this is not so. Indeed, about two thirds (63.4 per cent) of students report they do not use the copy/paste function without proper referencing. Moreover, due to the students' reports they do not use the Internet too often to perform assignments: 27.4 per cent report they never do it, 42 per cent report they use it several times a year and only about one third of students (31.1 per cent) report they do it often enough - once a month or more. Even more, the reported cases of plagiarism tend to decrease with the increase of an academic year: whereas about half ( 48.6 per cent) of first year students confess they plagiarize, as many as two times fewer (23.2 per cent) third year students report the same. Also, junior students less often report they feel guilty plagiarizing.

These results might be interpreted in such a way that students (at least about two thirds of them) reject plagiarism due to their inner moral responsibility, and the morals of the third year students is superior to the morals of juniors. This explanation is positive, since the goals of the University-level education include transfer of both knowledge and moral responsibility. Thus, the more classes take the students, the greater is their responsibility, at least supposedly. Additionally, the more classes a student takes, the greater is his/her understanding of which actions are illicit and/or dishonest.

Another possible interpretation, which is not alternative to the above one, lies in the specifics of undergraduate education in Russia. Students have a rather limited choice of classes, since most of the undergraduate classes are obligatory. All the classes can be roughly divided into professional ones and non-professional ones - the latter include foreign language, basics of economics and philosophy, often - world history and culture studies and some other disciplines, dependent on particular university. Traditionally, non-professional classes are the least popular taken all the generations of science students. The strictly professional education - special courses tailored to each specialization - often starts at the third academic year, though basic science courses such as physics, mathematics, biology, chemistry, etc. are taught during the first two years. It is important to note that the most part (but certainly not all) of exams have to be passed in an oral form. Exams are given twice a year, and a coursework is to be submitted once an academic year; during the semesters students have rather few assignments to be submitted in a written form.

The assignments in the least popular non-professional disciplines are the most likely to be plagiarized each time when students have to submit a paper in a written form: for each non-professional discipline, students might submit such a paper once or twice a year during the first two academic years. There is a great variety of such papers uploaded on web sources, and since the themes are often repetitive, the papers placed at a website a year or several years ago might well fit. On the contrary, assignments referring to professional education (the third and ongoing academic years) are less often repetitive, and the choice of web-placed papers is rather restricted - that means, taking a paper from the web and handing it in is more risky, compared to nonprofessional papers.

We can conclude that normally, Russian undergraduate science students may use a web-placed material and hand it in without changes as often as several times a year, whilst they are junior (first and second year) students, and have a much less need to do so when they are third-year students. That is exactly what the vast majority of students confess they do, since only 6.8 per cent report they would never plagiarize, under any condition. It is worth noting that about the same number, only 6.2 per cent of students reply they believe that their mates do not plagiarize. Also, it is very close to what Dr. Helene Marcoux, board member of The Center for Academic Integrity, a group of 320 colleges in the USA, said: "95 percent of students have admitted to cheating at some point in their education" (Roeschke, 2004).

Although undergraduate science students in Russia may plagiarize only several times a year, this is enough to call the most of them plagiarizers, and even heavy plagiarizers, since they have no special need to plagiarize more often. Every possible reason out of the requested ones seems worth for them to do plagiarizing, including time pressure, urgency and laboriousness of the assignments, high likeability to fail, and even no reason at all: any time. About half (44.5 per cent) of them would not feel guilty to plagiarize. 
We can assume that some of them, especially the junior ones, do not fully realize, and their academic administrators and tutors might have failed to inform them, that using simple copy/paste function without proper referencing means dishonesty: this sort of ill-doing does not seem to be widely known to students. The tutors are likely to be the key persons to filter cases of plagiarism out and to stop its epidemics-type development. Right now, nevertheless, it is unlikely that the tutors are either filtering plagiarism out or making attempts to stop it: about two thirds (60 per cent) of students are not sure if their tutor's expertise is high enough to recognize plagiarism, and besides every fourth (24.7 per cent) student reports that it is worth plagiarizing even if their tutors would certainly recognize it. Even taken that the tutors' expertise is high enough, the students are not sure they would bother to find out pieces taken from the Internet, would reject the assignment and blame or try to dispel dishonest students.

In fact, most often the faculty members would simply demand that the student do the plagiarized assignment again and do no not use the web sources. Thus, students do not risk too much when they hand in a dishonest product. To the best of the authors' knowledge, not all the universities in Russia openly demand that students entering the University never perform plagiarism in any form, including taking materials from the Internet. Hopefully the number of these open demands is going to increase.

\section{Conclusion}

The study has shown that undergraduate science students in Russia locate themselves within the mainstream of world-wide community of dishonest students who keep web-plagiarizing, i.e. taking materials from the Internet and handing these materials in as their own assignments. Russian students are mostly competent in the use of the Internet, and use it quite often; they report to have rather few moral barriers towards plagiarizing; they believe most of their mates do the same; they are not sure their tutors are able and are willing to recognize cheating; finally, they are competent enough in English and are hypothetically able to plagiarize materials in two languages.

\section{Acknowledgments}

The author is thankful to Dr. Attila Szabo for numerous discussions of the problem area and for presenting the questionnaire to measure plagiarism. The author thanks his assistants - psychologists Ksenia Reitzen who collected the materials, and Stanislav Seniushschenkov who handled the data. Associate professors Boris Aliev, Natalia Berezanskaya, Olga Gordeeva, and Joseph Krichever participated in the study when they let the research assistant collect data during their lectures.

\section{References}

Ang, A.Y., and Lo, B.W.N. (2001). Software piracy attitudes of tertiary students in Australia. From www.hkcs.org.hk/searcccd/ed11_aa.htm.

Cronan, T.P., and Kreie, J. (2000). Making ethical decisions. Communications of the ACM, 43. P. 66-71.

Debnath, N., and Bhal, K.T. (2002). Religious belief and pragmatic ethical framework as predictors of ethical behaviour. In F. Sudweeks, and Ch. Ess (eds.). Cultural Attitudes towards Technology and Communication. Proceedings of the 3rd International Conference. P. 409-420.

Earl, T. (2004). Internet Plagiarising Student Sues University. From www.webuser. co.uk/49305.html.

Jackson, L.A. et al. (2008). Cultural differences in morality in the real and virtual worlds: A comparison of Chinese and U.S. Youth. CyberPsychology \& Behavior, 11(3). P. 279-286.

Kim, K.H. (2003). A study of the conduct of Korean IT participants in ethical decision making. Lecture Notes in Computer Science, 2713. P. 64-74.

Kini, R.B., Ramakrishna, H.V., and Vijayaraman, B.S. (2003). An exploratory study of moral intensity regarding software piracy of students in Thailand. Behaviour and Information Technology, 22. P. 63-70.

Kolb, J.A., et al. (2003). Communicating about ethics in classroom and training situations: Special issues related to multicultural audiences. In. B. Schwom, and L. Beamers (eds.). Conference Proceedings of the Association for Business Communication, Section 9, 1-6. The Association for Business Communication, New York. From http://www.businesscommunication.org/conventions/procedings.html.

Langford, D. (ed.). (2000). Internet Ethics. Macmillan Press, Houndmills et al.

Loch, K.D., and Conger, S. (1996). Evaluating Ethical Decision Making and Computer Use. Communications of the ACM, 39. P. 74-83.

McGuire, Sh., et al. (2002). Teenagers self-reported motivations for participating in computer crime. In 8th International Conference on Motivation (Workshop on Achievement and Task Motivation). Abstracts. Moscow. P. 72-73. 
Quigley, M. (ed.). (2005). Information Security and Ethics: Social and Organizational Issues. Hershey-London-Melbourne-Singapore: IRM Press.

Roeschke, J. (2004). Faculty Look for Cheaters on Web Site. The State News, MSU's Independent Voice. September $2^{\text {nd }}$. From http://www.statenews.com/article. phtml?pk=25184.

Ruf, B.M., and Thomas, S.B. (2003). Unethical decision-making with computer usage in a university environment. From http://aaahq.org/AM2003/EthicsSymposium/ Session\%205a3.pdf.

Schultz, R.A. (2006). Contemporary Issues in Ethics and Information Technology. Hershey-London-Melbourne-Singapore: IRM Press.

Schwartau, W. (2001). Internet \& Computer Ethics for Kids (and Parents\&Teachers Who Havent Got a Clue). Inter-Pact.

Szabo, A., and Underwood, J. (2004). Cybercheats: Is Information and Communication Technology Fuelling Academic Dishonesty? Active Learning in Higher Education, 5, 2. P. 196-215.

Tavani, H.T. (2004). Ethics \& Technology: Ethical Issues in an Age of Information and Communication Technology. Wiley, New York.

Underwood, J., and Szabo, A. (2003). Academic Offences and E-Learning: Individual Propensities in Cheating. British Journal of Educational Technology, 34, 4. P. 467-477.

Voiskounsky, A. (2004). Current problems of moral research and education in the IT environment. In K. Morgan, C.A. Brebbia, J. Sanchez, A. Voiskounsky (eds.). Human Perspectives in the Internet Society: Culture, Psychology and Gender. Southampton, Boston: WIT Press. P. 33-41.

Voiskounsky, A.E., Babaeva, J.D., and Smyslova, O.V. (2000). Attitudes towards computer hacking in Russia. In D. Thomas, and B. Loader (eds.). Cybercrime: Law Enforcement, Security and Surveillance in the Information Age. Routledge, L. \& N.Y. P. 56-84.

Whitman, M.E., Townsend, A.M., and Hendrickson, A.R. (1999). Crossnational differences in computer-use ethics: A nine-country study. Journal of International Business Studies, 30. P. 673-687. From http://copenhagen.jibs.net/ Archive/1999/30_4_99_673.pdf. 